duration of consultation was 21 minutes. The most frequent topics of consultation: potential drug interactions $36 \%$, correct use of drugs $19 \%$, drug side effects $6.5 \%$, weight loss $6.5 \%$. Pharmacist interventions included the recommendation 'how to use it' $57.4 \%$, replacement and/or discontinuatio of drugs $6.4 \%$, diet and lifestyle change $14.9 \%$. The number of patients who visited the consultation centre repeatedly according to the recommendations, was 17 (68\%) in 2011 and 13 (59\%) in 2012.

Conclusions Patient-orientated care in pharmacy consultation centre enables us to prevent the patients from using the drugs incorrectly. Analysis of the data showed a variety of interventions by the hospital pharmacists, who helped patients with their problems by several repeated consultations.

No conflict of interest.

\section{OHP-064 PHARMACEUTICAL EXPENSES FOR WELFARE OUTPATIENTS AND POLITICAL REFUGEES IN A PAEDIATRIC ATHENS HOSPITAL, DURING 2011 AND FIRST HALF OF 2012}

doi:10.1136/ejhpharm-2013-000276.437

M Angelakou, N Kouri, P Menegakis. Hospital Aglaia Kyriakou, Pharmacy, Athens, Greece

Background In Greece the expense of public pharmaceuticals (medicines prescribed by hospitals and public insurance funds) in 2009 was 5.1 billion corresponding to $2.4 \%$ of GNP, while the corresponding average rate for OECD countries was 1.5\%. In 2012 the target is 2.88 billion. In addition, following the country's enrolment in the financial stability mechanism in 2010, the NHS (National Health System) was substantially enlarged because of the increased demand for public health system services while simultaneously there were cuts in NHS financing due to austerity measures.

Purpose To record and evaluate the pharmaceutical expenses due to the outpatients covered by Social welfare and the political refugees which all were served by the paediatric hospital pharmacy during 2011 and the first half of 2012 .

Materials and Methods Information was acquired from the hospital pharmacy computerised data system.

Results During 2011,1250 prescriptions covered by welfare insurance were dispensed, of which $91 \%$ concerned children of Greek citizenship, and $9 \%$ immigrant children with political refugee documentation (mainly from Nigeria, Iraq, Afghanistan, Ethiopia and Syria).

The total cost was 113,525 euro. The first semester of 2012830 prescriptions were dispensed costing 96,180 euro of which $86.5 \%$ were for children of Greek citizenship and the other $13.5 \%$ was for children with refugee status.

\section{Conclusions}

1. The pharmaceutical expenses concerning children covered by the welfare system and refugee children are increasing rapidly (especially for refugee children)

2. Given the current crisis in Greece, we urgently have to devise an effective policy to control the increasing pharmaceutical expenditure.

No conflict of interest.

\section{OHP-065 PHARMACEUTICAL SERVICES IN HOSPITALS IN SERBIA}

doi:10.1136/ejhpharm-2013-000276.438

II Popovic, ${ }^{2 T}$ Savkovic, ${ }^{3} \mathrm{D}$ Krupnikovic, ${ }^{4} \mathrm{~A}$ Tadic, ${ }^{5 \mathrm{M}}$ llic, ${ }^{6} \mathrm{D}$ Loncarevic, ${ }^{7} \mathrm{~S}$ Vezmar Kovacevic, "'B Miljkovic. 'Institute of oncology and radiology of Serbia, Hospital Pharmacy, Belgrade, Serbia; 'Zvezdara University Medical Center, Hospital Pharmacy, Belgrade, Serbia; ${ }^{3}$ Clinical Center Serbia, Hospital Pharmacy, Belgrade, Serbia; ${ }^{4}$ Health Center Uzice, Hospital Pharmacy, Uzice, Serbia; ${ }^{5}$ nstitute for Orthopaedic Surgery Banjica, Hospital Pharmacy, Belgrade, Serbia; ${ }^{6}$ Medical Center Bezanijska Kosa, Hospital Pharmacy, Belgrade, Serbia; 'Faculty of Pharmacy University of Belgrade, Clinical Pharmacy and pharmacokinetics, Belgrade, Serbia
Background The role of hospital pharmacists is changing worldwide. Pharmacists are becoming more and more involved in the treatment of patients and the provision of pharmaceutical care (PC). Consequently, increased numbers of pharmacists in hospitals are necessary and/or better organisation of traditional activities.

Purpose To identify the number and categories of pharmaceutical services and time frame for such activities in order to improve the organisation of pharmaceutical services in hospitals.

Materials and Methods The research was conducted in 21 hospital pharmacies out of 61 . Data were collected through a questionnaire, which contained 51 pharmaceutical services classified into 12 categories. Services were defined by the Section for hospital pharmacies in Serbia in accordance with the conclusions of the global conference regarding the future of hospital pharmacy (Basel 2008).

Pharmacists were asked if they practise certain types of service, how often and how much time they consume for each service they practise.

Results The average number of pharmacists in a hospital pharmacy was two but varied between 1 and 6 . A pharmacist provided on average 30 services per day (15-42). On average during workdays pharmacists devoted most of their time to: data processing $(28 \%$; $2.1 \mathrm{~h})$, dispensing drugs $(23 \% ; 2 \mathrm{~h})$, ordering $(12 \% ; 1 \mathrm{~h})$ and supply $(10 \%$; $45 \mathrm{~min})$, while the share related to PC was only $8 \%$ or 35 minutes per day.

Conclusions The results of research showed that supply and storage of medicines are the most frequent and time-consuming activities. Therefore, not enough time is left for patients and PC. Finally, in order to improve pharmaceutical activities in Serbia it is necessary to increase the number of pharmacists in hospitals, consolidate procurement across the region and streamline data processing services.

No conflict of interest.

\section{OHP-066 PHARMACOECONOMIC EVALUATION OF FOLLICLE- STIMULATING HORMONE (URINARY VS. RECOMBINANT) IN CONTROLLED OVARIAN HYPERSTIMULATION}

doi:10.1136/ejhpharm-2013-000276.439

JM Martínez-Sesmero, M García Palomo, AR Rubio Salvador, JJ Cía Lecumberri P Moya Gómez. Hospital Virgen de la Salud, Pharmacy, Toledo, Spain

Background Controlled ovarian hyperstimulation $(\mathrm{COH})$ is mainly based on management of follicle-stimulating hormone (FSH). FSH may be obtained from the urine of menopausal women (u-FSH) or through recombinant biotechnology (r-FSH).

Purpose To conduct a pharmacoeconomic evaluation of different FSH (u-FSH vs. r-FSH) in $\mathrm{COH}$.

Materials and Methods We conducted a bibliographic review to compare the efficacy of $\mathrm{u}-\mathrm{FSH}$ and r-FSH in $\mathrm{COH}$ (Database: PubMed, keywords: FSH and $\mathrm{COH}$, randomised and controlled clinical trials, from 2005 to 2011). The efficacy indicators were: progression rate in pregnancy (pregnancy remained at 12 weeks) and the number of mature oocytes obtained. We determined the cost per unit of efficacy (using current Spanish drug prices in 2012) and the incremental cost-efficacy ratio (ICER) with their sensitivity analysis. Setting: Assisted Reproduction unit in tertiary teaching hospital that serves an average of 340 patients per year. Statistical analysis powered by SPSS 15.0 .

Results We analysed 10 clinical trials in women being treated with $\mathrm{COH}$. The pooled data of the progression of pregnancy was $26.2 \%$ (FSH-r) vs. $22.3 \%$ (FSH-u) (difference $=3.9 \%$; 95\% CI $=1.2-5.9$ ), and the average number of mature oocytes was: 9.0 (FSH-r) vs. 7.1 (FSH-u) (difference $=1.9 ; 95 \% \mathrm{CI}=0.7$ to 4.1 ). The cost per pregnancy for $r-F S H$ was $€ 2,832.3(€ 1,628.2-€ 3,754.3)$ and $€ 2,332.5$ $(€ 1,526,1-€ 2,884.7)$ for $\mathrm{u}-\mathrm{FSH}$, so that the ICER in the pregnancy rate was 128.1 (85.1-147.4). The cost per number of mature oocytes 
obtained for r-FSH was €82.3 (€78.3-€98.1) and €73.3 (€67.6-€81.7) for $\mathrm{u}-\mathrm{FSH}$, so the ICER in mature oocytes obtained was 4.7 (4.0-15.2).

Conclusions According to scientific evidence r-FSH appears to be more effective in women undergoing $\mathrm{COH}$; however, this slight increase in efficacy does not seem to compensate for the difference in price, the result being that u-FSH is more cost effective.

No conflict of interest.

\section{OHP-067 PRESCRIPTION PROFILE ANALYSIS OF PROTON PUMP INHIBITORS IN A TERTIARY HOSPITAL}

doi:10.1136/ejhpharm-2013-000276.440

A Díez Alcántara, V Saavedra Quirós, E Santiago Prieto, A Torralba Arranz. Hospital Universitario Puerta de Hierro, Pharmacy, Madrid, Spain

Background In October 2011, selection criteria for proton pump inhibitors (PPIs) were published, recommending the use of omeprazole as a drug of choice because, at equipotent doses, it is the most cost-effective drug, compared to other PPIs.

Purpose To describe the prescription profile of PPIs for different consultants and in patients who are discharged from hospital.

Materials and Methods Information about the prescriptions for PPIs issued during 2011 was obtained from the pharmaceutical software. The data were analysed and classified according to therapeutic group, active principle, number of defined daily doses (DDDs), service and number of prescriptions. The percentage DDD of each active principle with respect to the PPI group as a whole was also investigated.

Results During 2011, 9.654 prescriptions were written. Gastroenterology was the Medical Service with the most prescriptions, followed by Internal Medicine and Otolaryngology. The percentage DDD of each PPI prescribed in each service, related to the whole of the PPIs was:

- Gastroenterology: 26\% omeprazole; $14 \%$ pantoprazole; 18\% lansoprazole; $16 \%$ esomeprazole; $26 \%$ rabeprazole. Total, 2213 prescriptions.

- Otolaryngology: $55 \%$ omeprazole; $22 \%$ pantoprazole; $2 \%$ lansoprazole; $7 \%$ esomeprazole; $14 \%$ rabeprazole. Total, 1074 prescriptions.

- Internal Medicine: $82 \%$ omeprazole; $7 \%$ pantoprazole; $0,5 \%$ lansoprazole; $10 \%$ esomeprazole; $0,5 \%$ rabeprazole. Total, 619 prescriptions.

Conclusions Omeprazole is the PPI with the highest percentage of DDD prescribed, nevertheless prescriptions for it are on the low side (less than 30\% in Gastroenterology and Otolaryngology, and less than $85 \%$ in Internal Medicine); this means that there is still a lot more room for improvement. The Service which made the best selection of IPPs was Internal Medicine, followed by Otolaryngology, and finally Gastroenterology.

Despite the low number of prescriptions made in hospital, compared to the ones prescribed in Primary Care, there is still a lot of work to be done to improve the selection of IPPs prescribed in hospital.

No conflict of interest.

\section{OHP-068 REPEAT AUDIT OF LMWH USE IN THROMBOPROPHYLAXIS ON AN ORTHOPAEDIC SURGERY WARD, EMERGENCY CENTRE, BELGRADE}

doi:10.1136/ejhpharm-2013-000276.441

M Kara-Jovanovi, RD Rajinac, JG Jevtic, SLJ Stojicevic, KM Klancnik. Clinical Center Serbia, Hospital pharmacy Emergency Center, Belgrade, Serbia

Background The Guideline for Prevention of Deep Venous Thromboembolism in Orthopedic Surgery, based on current European and American Guidelines, was introduced in late 2009 on the Orthopedic Surgery Ward, Emergency Centre, Belgrade.
Hospital pharmacists were actively involved in writing, and monitoring the implementation of, the guideline.

Purpose The first audit of implementation of the guideline was in March 2010. The aim was to show if all patients were receiving thromboprophylaxis according to the guideline; and whether thromboprophylaxis was being recommended for patients after discharge from hospital.

The aim of the repeat study was to estimate if there were differences in implementing the guideline.

Materials and Methods Monitoring of prescriptions for patients in hospital and recommendations for thromboprophylaxis on the discharge documentation.

This study covered the period from January to March 2012 and compared results with the same period in 2010.

Results 2010 year: Total number of patients 104; 97\% of patients received the recommended anticoagulant treatment during hospitalisation, and $85 \%$ patients received the recommended anticoagulant treatment after hospitalisation.

2012 year: Total number of patients 143; 96.5\% of patients received the recommended anticoagulant treatment during hospitalisation, and $91.5 \%$ of patients received the recommended anticoagulant treatment after hospitalisation.

Conclusions During the monitoring period 3\% of patients did not receive the recommended thromboprophylaxis during hospitalisation in 2010 , and $3.5 \%$ of patients in 2012 .

By continuous monitoring of recommended thromboprophylaxis after release from hospital, it was concluded that $15 \%$ of patients failed to receive the recommended treatment in 2010, and $8.4 \%$ in 2012 .

The repeat audit two years later showed a similar percentage of thromboprophylaxis prescribing during hospitalisation, and significant improvement in thromboprophylaxis recommendations at the discharge of patients from hospital.

No conflict of interest.

\section{OHP-069 RETROSPECTIVE STUDY ABOUT PATIENTS WITH A STOMA AND THEIR NEEDS IN THE HEALTH DISTRICT OF PATTI (MESSINA)}

doi:10.1136/ejhpharm-2013-000276.442

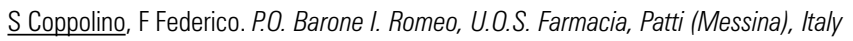

Background Serious conditions of the bowel and bladder often require the formation of a stoma. It is estimated that 650,000 people in Europe live with a stoma. A person with a stoma not only needs post-operative medical care, but also appliances and accessories to increase his quality of life. In the Local Health Authority (LHA) of Messina appliances and accessories are given, for free, every month by the Hospital/District Pharmacies.

Purpose To point out, for the Health District (HD) of Patti, which is one of seven HDs in the LHA of Messina, the number of patients with a stoma, the types of appliances and accessories used, and with what difficulties we assist patients.

Materials and Methods Through the retrospective interrogation of an administrative database it was possible to assess the number of patients with a stoma who live in the HD of Patti and, particularly, those who received appliances and accessories from 01/01/2011 to $31 / 12 / 2011$. For each patient the gender, age, kind of stoma, type and amount of appliances and accessories were recorded. All data gathered were analysed with 'Statistica' software. During the delivery of devices patients were also interviewed about problems they had experienced. All answers were collected and reviewed anonymously.

Results 70 patients were recorded, mainly with a colostomy. The incidence in the HD population was $1: 715$ inhabitants. $55.7 \%$ of patients were males and the average age was 74.3 years $[39,94]$. 